HUNGARIAN AGRICULTURAL ENGINEERING

$N^{\circ} 28 / 2015$ 44-47

Published online: http://hae-journals.org/

HU ISSN 0864-7410 (Print) / HU ISSN 2415-9751(Online)

DOI: 10.17676/HAE.2015.28.44
PERIODICAL OF THE COMITTEE OF AGRICULTURAL AND BIOSYSTEM ENGINEERING OF

THE HUNGARIAN ACADEMY OF SCIENCES and

SZENT ISTVÁN UNIVERSITY

Faculty of Mechanical Engineering

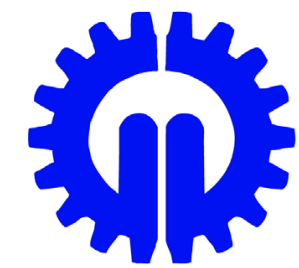

\title{
CORRELATION BETWEEN DIELECTRIC PROPERTIES AND AEROBIC BIODEGRADABILITY OF MEAT PROCESSING SLUDGE
}

\author{
Author(s): \\ S. Beszédes ${ }^{1}-$ P. Veszelovszki² - B. Lemmer ${ }^{1}-$ L. Ludányi $^{1}-$ G. Keszthelyi-Szabó1 - C. Hodúr ${ }^{1}$
}

Affiliation:

'Department of Process Engineering, Faculty of Engineering, University of Szeged, Moszkvai blvd. 9, Szeged, H-6725

${ }^{2}$ Technical Institute, Faculty of Engineering, University of Szeged, Moszkvai blvd. 9, Szeged, H-6725, Hungary

\section{Email address:}

beszedes@mk.u-szeged.hu, veszelov@mk.u-szeged.hu, lemmer@mk.u-szeged.hu ludanyi.lajos@gmail.com, szabog@mk.u-szeged.hu, hodur@mk.u-szeged.hu

\begin{abstract}
The dielectric properties, namely the dielectric constant and the dielectric loss factor are important for predicting the behavior of materials during microwave processing, because both of them determine the interaction between the molecules with the oscillating electromagnetic field. Because the dielectric properties are not known for food industry sludge, our main aim was to measure the dielectric constant and dielectric loss factor for meat industry sludge, and to investigate the correlation between the dielectric parameters and the biodegradability indicators. Our experimental results show, that despite of the high moisture content of sludge, temperature depending behavior of $\varepsilon$ ' was different that of can be known for water. Sludge had a decreasing tendency in the temperature range of $20-60^{\circ} \mathrm{C}$, but over a critical value of the temperature increasing induced an increment in the value of $\varepsilon$ '.

Our experimental results verified that the change of sCOD/tCOD has a good linear correlation with the dielectric loss factor. Similar to the trends determined for the solubility change, a good correlation was found between the dielectric loss factor and the change of biodegradability measured by the BOD/tCOD parameter. Our experimental results verified that the change in the value of dielectric loss factor correlate with the disintegration degree and the biodegradability of sludge, as well Correlation between the electrical parameters and biodegradability indicators enable to develop a real-time and in-line measuring and control system for batch and continuous flow microwave sludge conditioning technology.
\end{abstract}

\section{Keywords}

dielectric properties, microwave, sludge, biodegradability

\section{Introduction}

Nowadays the renewable energy generation can be often connected to waste management technologies. For example, since an effective utilization of food industrial biomass waste has desired, the establishment and optimization of an efficient biogas production process from these waste materials is very important from perspectives of both energy and environmental issues. Food industry generates a huge amount of liquid and solid organic waste and by-products. Beside the considerable environmental risk of waste, it has a good potential to indirect bio-energy production for example in anaerobic digestion (AD) process. Biofuel production from agri-food wastes can also contribute to make waste management more socially acceptable, sustainable and cost effective.

Wastewater sludge originated from food processing has high organic matter content, but the biodegradability is limited due to the structure and the low level solubility of organic matters. Degree of hydrolysis is one of the key issues for the whole efficiency of the sludge utilization processes. In hydrolysis the polymeric, insoluble compounds, such as proteins, fats carbohydrates and their derivatives are decomposed into less molecules, such as amino acids, monosaccharaides, alcohols or fatty acids. Due to the complex particle structure and the presence of strong cell membranes sludge is difficult to bio-degrade under aerobic or anaerobic conditions, as well. The main aim of sludge pre-treatment technologies is to disrupt the cell membranes, thus lysis of the cells of microorganisms, and to accelerate the hydrolysis of macromolecular components.

Among the different sludge handling methods, microwave irradiation is successfully applied in the process of hygienization, dewatering, drying and pre-treatment stage of anaerobic digestion (AD). A microwave method is suitable to increase the degree of conversion of organic matters contained in the sludge flocks into easily accessible compounds for fermentative microorganisms. Disruption of cell membranes led to release of the protoplasm-enzymes responsible for the increasing of ammonia and phosphate concentration in sludge liquor [1]. The major advantage of MW heating over conventional thermal methods is the volumetric heating, which leads to faster heat and mass transfer and shorter process time. Application of MW irradiation combining with the oxidation process, such as ozonation, can also be considered to be promising technology as pre-treatment before $\mathrm{AD}$ of high organic matter containing but less degradable sludge [2].

Energy transfer carried by microwave irradiation affect the biodegradability of materials in two ways. Thermal effect is expressed in the increase of internal pressure of intracellular liquor caused by internal heating and rapid evaporation, which altogether can lead to cell wall disruption [3]. The non-thermal effect of high frequency electromagnetic field contributes to alter the structure of macromolecules with polarization of side chains and breaking of hydrogen bounds [4, 5]. High efficiency of MW treatments in the biomaterial processing and also on the rate of 
chemical reactions is often explained by the non-thermal effects of microwaves due to the direct interaction of electromagnetic field with molecules [6]. MW irradiation has been successfully adopted as pre-treatment method via the high energy dissipation of polar compounds of sludge.

The most used method to characterize the change in the efficiency of disintegration is the measure of the soluble to total chemical oxygen demand (SCOD/TCOD). Lysis of microbial cell walls and disintegration of sludge flocks is determined by hydrogen bindings, hydrophobic interactions and also by the concentration of divalent cations. Increment of $\mathrm{Ca}^{2+}$ and $\mathrm{Mg}^{2+}$ as a component of phospholipids is due to the disruption of cell walls [7]. Therefore the measurement of divalent ion concentration in liquid phase can be an indirect method to follow the degree of disintegration. Additionally, the strong effect of microwave irradiation on the cell wall disruption and sludge flock disintegration was confirmed by microscope observations [8]

Results of preliminary studies established that organic matter releasing is mainly influenced by the final temperature and temperature ramp of sample during the process and the length of microwave irradiation. If the final temperature is higher than $80^{\circ} \mathrm{C}$ a partial conversion of $\mathrm{NH}^{4+}$ into gas phase as $\mathrm{NH}^{3}$ can be observed, decreasing the organic matter concentration of liquid phase [9]. Furthermore if the temperature of sample reach the boiling point a slight decrease of COD concentration occurred [8]. Because the heat stress is influenced by the temperature ramp which is depended on the strength of electromagnetic field, the power of microwave irradiation can be also determinative process parameter [10].

Numerous reports concluded that microwave pre-treatment is suitable to enhance the efficiency of anaerobic digestion process, what manifested in higher biogas product and accelerated biogas production rate $[11,12]$. The increment of biogas production and utilization value of biogas (calorific value and quality determined mainly by the methane, carbon dioxide and hydrogen sulfide concentration) is affected by the type of processed sludge [13].

Microwave heating depends on the ability of electromagnetic (EM) field to polarize the molecules or atoms. Depending of the frequency of EM field the dipoles and ions in solutions and suspensions is moving with time lead to energy dissipation. The behavior of molecules of the material in EM field is characterized by the dielectric parameters. The measurement of dielectric properties is widely used in many field of researches. The value of permittivity or dielectric constant provides information about the polarization and relaxation response of molecules in the electromagnetic field. Dielectric loss factor indicate the transmission loss of electromagnetic waves in the material [14].

The dielectric properties, namely the dielectric constant $\left(\varepsilon^{\prime}\right)$ and the dielectric loss factor ( $\varepsilon ")$ are important for predicting the behavior of materials during microwave processing, because both of them determine the interaction between the molecules with the oscillating electromagnetic field [3]. Dielectric constant measure the ability of material to store the irradiated energy, the value loss factor relate to the ability of material to convert electric energy into heat [15].

The value of dielectric parameters are depend on the frequency and the physical and chemical properties of irradiated sample, such as moisture content, temperature, chemical composition, the form of water bounding, the migration ability of polar and dipole components and the chemical or structural change during the microwave treatment [16]. The dielectric loss factor significantly increases with increasing concentrations of dissolved ions. But dielectric loss factor decrease with increasing of temperature at the most widely used $2450 \mathrm{MHz}$ frequency. The relaxation time of bound water molecules is longer than that of free water [17]. Because the bound water is associated by with proteins and carbohydrates in cell membranes and sludge flocks, the disruption and structural change cause change in dielectric properties, as well.

The sludge pretreatments aim to modify the sludge structure, disrupt the cell walls causing liberation of intracellular components $[7,18]$ what affect the biodegradability and the dielectric parameters, as well. Therefore the measurement of the change of dielectric properties induced by the pre-treatments, or the real-time measurement of them during the microwave and/or chemical and oxidation procedure enable to develop novel process control and optimization method for laboratory and industrial scale application.

Because the dielectric properties are not known for food industry sludge, our main aim was to measure the dielectric constant and dielectric loss factor for meat industry sludge, and to investigate the correlation between the dielectric parameters and the biodegradability indicators.

\section{Materials and methods}

Investigated wastewater sludge was originated from meat industry with a total solid (TS) content of $9.7 \%$, initial total COD of $105.9 \mathrm{kgm}^{-3}$, and soluble COD of $20.1 \mathrm{kgm}^{-3}$. The chemical oxygen demand of sample was measured triplicated using colorimetric standard method.

COD in supernatant was determined after separation by centrifugation (12,000 rpm for 10 minutes) and prefiltration $(0.45$ $\mu \mathrm{m}$ Millipore disc filter).

The biochemical oxygen demand (BOD5) measurements were carried out in a respirometric BOD meter (BOD Oxidirect, Lovibond, Germany), at $20^{\circ} \mathrm{C}$ for 5 days

Dielectric constant $\left(\varepsilon^{\prime}\right)$ and dielectric loss factor $\left(\varepsilon^{\prime \prime}\right)$ were determined in a tailor made dielectrometer equipped with a dual channel NRVD power meter (Rohde \& Schwarz). Magnetron of dielectrometer operates at a frequency of $2450 \mathrm{MHz}$. $\varepsilon$ ' and $\varepsilon$ ” was calculated from the reflection coefficient $(\Gamma)$, phase shift $(\phi)$, incident $\left(\mathrm{P}_{\mathrm{i}}\right)$ and reflected power $\left(\mathrm{P}_{\mathrm{r}}\right)$.

$$
\begin{gathered}
\delta=\operatorname{arctg}\left(\frac{|\Gamma| \sin \varphi}{1-(|\Gamma| \cos \varphi)}\right)-\operatorname{arctg}\left(\frac{|\Gamma| \sin \varphi}{1+(|\Gamma| \cos \varphi)}\right) \\
\varepsilon^{\prime \prime}=\operatorname{tg} \delta \cdot \varepsilon^{\prime} \\
\varepsilon^{\prime}=\sqrt{\frac{P_{r}}{P_{i}}}
\end{gathered}
$$

\section{Results and discussion}

In the first series of our experiments the dielectric constant $\left(\varepsilon^{\prime}\right)$, the dielectric loss factor ( $\varepsilon ")$ and temperature dependency of them were determined. For the analysis two sludge sample were used with different dry matter content (SL1 $=9,7 \mathrm{w} \%$; and SL2 $=14,8$ w\%). SL2 sludge was prepared from SL1 sludge by addition of concentrated sludge fraction to achieve higher dry matter content.

The temperature range of measurements was $20-80^{\circ} \mathrm{C}$ to avoid boiling, because bubbles containing vapor disturb the analysis of dielectric parameters in the measuring cell of dielectrometer used in our experiment. Fluctuation of dielectric parameters can occur when boiling point is reached during the heating, or air bubbles are arisen in the fluid.

Our experimental results show, that despite of the high moisture content of sludge, temperature depending behavior of $\varepsilon$ ' was different that of can be known for water. SL1 sludge had a decreasing tendency in the temperature range of $20-60^{\circ} \mathrm{C}$, but over a critical value of the temperature increasing induced an 
increment in the value of $\varepsilon$ '. SL2 sludge with higher dry matter content had a different behavior as a function of temperature, because over the temperature of $60^{\circ} \mathrm{C}$ increment of $\varepsilon$ ' was not significant.

Change of dielectric loss factor, as the function of temperature, has a similar tendency to $\varepsilon$ ' for SL1 sludge. Contrary to the different behavior of $\varepsilon$ ', tendency of the change in the value of $\varepsilon$ " for SL1 was similar to that of measured for SL2 (Figure 1). The temperature depending breaking point for $\varepsilon$ " was different for the two type of sludge with different dry matter content.

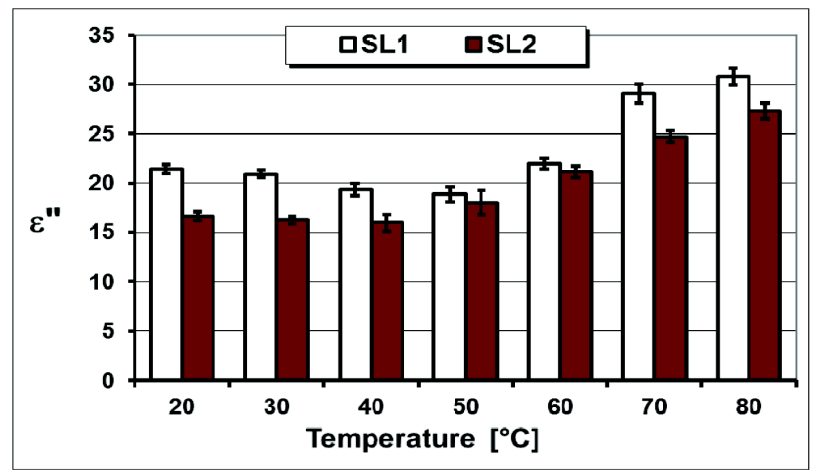

Figure 1. Change of dielectric loss factor with temperature

After decreasing phase the value of $\varepsilon$ " starts to increase at $50^{\circ} \mathrm{C}$ and $40^{\circ} \mathrm{C}$ for SL1 and SL2 sludge, respectively. Therefore, it can be concluded, that the value of dielectric loss factor was influenced by the temperature moisture content of sludge, as well. Because the quantity of sample and the water content was not changed during the measurement the special behavior of $\varepsilon$ " was assumed to the structural change of sludge.

In order to find explanation for the change of $\varepsilon$ " and to confirm our hypothesis on structural change, in other experimental series the ratio of soluble chemical oxygen demand (SCOD) to the total chemical oxygen demand (tCOD) was determined, which correlate the disintegration degree and the solubility of sludge organic matters. Our experimental results verified that the change of sCOD/tCOD has a good linear correlation with the dielectric loss factor (Figure 2).

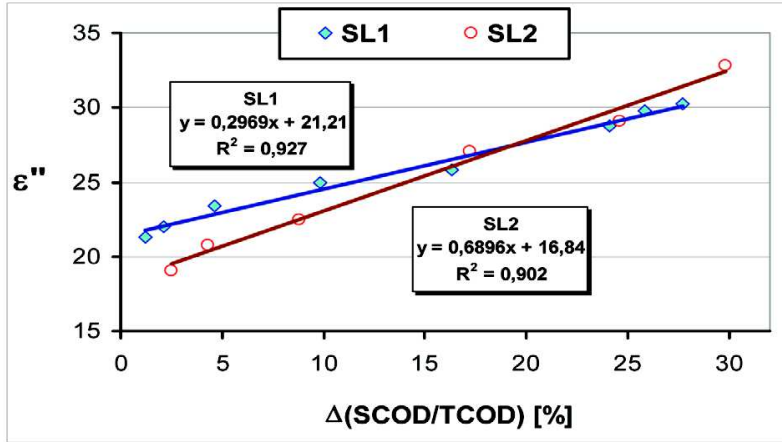

Figure 2. Correlation of dielectric loss with the change of organic matter solubility

The thermal treatments resulted in the disruption of cell wall and disintegration of sludge structure what has an increasing effect of the ratio of fee water content to the bounded water in the sludge. On the other hand, the degraded cell walls led to the liberation of intracellular substances and the hydrolysis of macromolecules resulted in a higher concentration and enhanced migration ability of ions and polar compounds. Above a certain temperature, when sludge disintegration reach a critical value, the change of dielectric parameters are more influenced by the ionic migration than the dipole rotation [6].

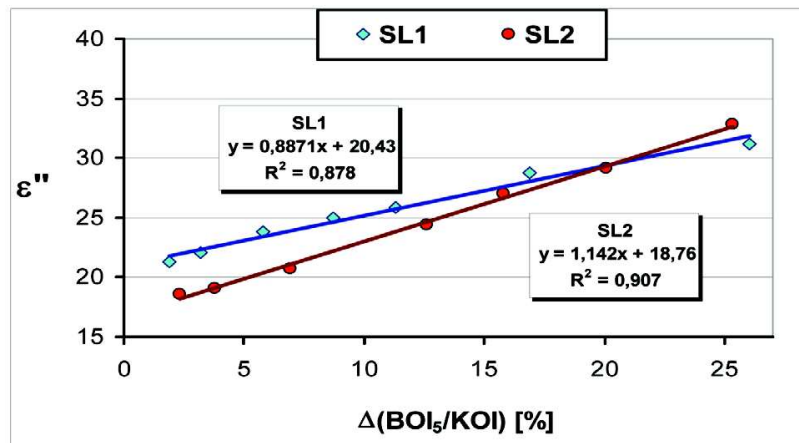

Figure 3. Relationship between dielectric loss factor and $\mathrm{BOD} / \mathrm{TCOD}$

On the other hand, the change in solubility of organic matter has also effect on biodegradability. The correlation between solubility and biodegradability given as the ratio of BOD to COD has been verified earlier [2]. Similar to the trends for the solubility change, a good correlation was found between the dielectric loss factor and the change of biodegradability measured by the BOD/tCOD parameter (Figure 3).

\section{Conclusion}

In our work the dielectric constant $\left(\varepsilon^{\prime}\right)$ and the dielectric loss factor $(\varepsilon ")$ was measured for a meat processing wastewater sludge. There was found, that $\varepsilon$ ' and $\varepsilon$ " decreasing with increasing temperature, but over a certain value of temperature (depending on the dry matter content of sludge) start to increase. This behavior of dielectric parameters is in a relationship with the structural change of sludge, which was characterized by the $\mathrm{sCOD} / \mathrm{tCOD}$ ratio and the biodegradability of organic matter content of sludge, which was given by the ratio of $\mathrm{BOD}_{5}$ to tCOD.

Our experimental results verified that the change in the value of dielectric loss factor correlate with the disintegration degree and the biodegradability of sludge, as well. Correlation between the electrical parameters and biodegradability indicators enable to develop a realtime and in-line measuring and control system for batch and continuous flow microwave sludge conditioning technology.

\section{Acknowledgements}

This project was supported by the János Bolyai Research Scholarship of the Hungarian Academy of Sciences. The members of research group are thankful for the financial support provided by the Hungarian Scientific Research Fund (OTKA), under contract number K105021. This research was realized in the frames of TÁMOP 4.2.4. A/2-11-1-2012-0001 „National Excellence Program - Elaborating and operating an inland student and researcher personal support system convergence program" The project was subsidized by the European Union and co-financed by the European Social Fund.

\section{References}

[1.] Appels L., Houtmeyers S., Dereve J., van Impe J., Dewil R.: 2013. Influence of microwave pre-treatment on sludge solubilization and pilot scale semi-continuous anaerobic digestion. Bioresource Technology Vol. 28, pp. 598-603. http://dx.doi.org/10.1016/j.biortech.2012.11.007 
[2.] Beszédes S., László Zs., Szabó G., Hodúr C.: 2009. Examination of the effect of microwave irradiation on the biodegradable and soluble fraction of organic matter of sludge. Annals of Faculty of Engineering Hunedoara-International Journal of Engineering, Vol. 7(4), pp. 87-90

[3.] Géczi G., Horváth M., Kaszab T., Alemany G. G.: 2013. No major differences found between the effects of microwavebased and conventional heat treatment methods on two different liquid foods. PLOS ONE Vol. 8(1), pp. 1-12 http://dx.doi.org/10.1371/journal.pone.0053720

[4.] Park B., Ahn J. H., Kim J., Hwang S.: 2004. Use of microwave pretreatment for enhanced anaerobiosis of secondary sludge. Water Science and Technology, Vol.50, pp.17-23

[5.] Lakatos E., Kovács A. J., Neményi M.: 2005. Homogenious microwave field creation. Hungarian Agricultural Engineering, Vol. 18, pp. 80-81

[6.] Leonelli C., Mason T. J.: 2010. Microwave and ultrasonic processing: Now s realistic option for industry. Chemical Engineering and Processing, Vol. 49, pp. 885-900. http://dx.doi.org/10.1016/j.cep.2010.05.006

[7.] Ahn J. H., Shin S. G., Hwang S.: 2009. Effect of microwave irradiation on the disintegration and acidogenesis of municipal secondary sludge. Chemical Engineering Journal Vol. 153, pp. 145-150. http://dx.doi.org/10.1016/j.cej.2009.06.032

[8.] Bohdziewicz J., Sroka E.: 2006. Application of hybrid systems to the treatment of meat industry wastewater. Desalination, Vol. 198, pp. 33-40. http://dx.doi.org/10.1016/ j.desal.2006.09.006

[9.] Eskicioglu C., Kennedy K. J., Droste R. L.: 2006. Characterization of soluble organic matter of waste activated sludge before and after thermal pretreatment. Water Research Vol. 40, pp. 3725-3736

[10.] Beszédes S., László Zs., Szabó G., Hodúr C.: 2011. Effects of microwave pretreatments on the anaerobic digestion of food industrial sewage sludge. Environmental Progress and Sustainable Energy, Vol. 30, pp. 486-492 http://dx.doi.org/ 10.1002/ep.10487
[11.] Park W. J., Ahn J. H., Hwang S., Lee C. K.: 2010. Effect of output power, target temperature, and solid concentration ont he solubilization of waste activated sludge using microwave irradiation. Bioresource Technology Vol. 101, pp. 13-16 http://dx.doi.org/10.1016/j.biortech.2009.02.062

[12.] Toreci I., Kennedy K. J., Droste R. L.: 2009. Evaluation of continuous mesophilic anaerobic sludge digestion after high temperature microwave pretreatment. Water Resource Vol. 43, pp.1273-1284

[13.] Sólyom K., Mato R. B., Perez-Elvira S. I., Cocero M. J.: 2011. The influence of the energy absorbed from microwave pretreatment on biogas production from secondary wastewater sludge. Bioresource Technology Vol. 102(23), pp. 10849-10854. http://dx.doi.org/10.1016/j.biortech.2011.09.052

[14.] Komarov V.: 2012. Handbook of dielectricand thermal properties of materials at microwave frequencies. Artech House, US, 2012, $169 \mathrm{p}$.

[15.] Zheng J., Kennedy K. J., Eskicioglu C.: 2009. Effect of low temperature microwave pretreatment on characteristic and mesophilic digestion of primary sludge. Environmental Technology, 2009:Vol. 30,pp. 319-327. http://dx.doi.org/10.1080/ 09593330902732002

[16.] Clark D. E., Folz D., West J. K.: 2000. Processing materials with microwave energy. Materials Science and Engineering A287, pp. 153-158 http://dx.doi.org/10.1016/S09215093(00)00768-1

[17.] Wang S., Tang J., Cavalierai R. P., Davis D.: 2003. Differential heating of insects in dried nuts and fruits associated with radio frequency and microwave treatments. Transaction ASAE Vol 46, pp. 1175-1182.

[18.] Cho S. K., Shin H. S., Kim D. H.: 2012. Waste activated sludge hydrolysis during ultrasonication: two-step disintegration. Bioresource Technology Vol. 44, pp. 480-483. http://dx.doi.org/ 10.1016/j.biortech.2012.07.024 